\title{
Multi-temporal airborne structure-from-motion on caldera rim: Hazard, visitor exposure and origins of instabilities at Piton de la Fournaise
}

Progress in Physical Geography 2019, Vol. 43(2) 193-214

(C) The Author(s) 2018

Article reuse guidelines: sagepub.com/journals-permissions DOI: |0.1 |77/0309|333|880820| journals.sagepub.com/home/ppg

@SAGE

\section{Allan Derrien}

Institut de Physique du Globe de Paris, Université Sorbonne Paris Cité, Univ. Paris Diderot, La Réunion, France

\section{Nicolas Villeneuve}

Institut de Physique du Globe de Paris, Université Sorbonne Paris Cité, Univ. Paris Diderot, La Réunion, France; Université de La Réunion, Institut de Physique du Globe de Paris, Sorbonne Paris Cité, Saint Denis, France

\section{Aline Peltier}

Institut de Physique du Globe de Paris, Université Sorbonne Paris Cité, Univ. Paris Diderot, La Réunion, France

\section{Laurent Michon}

Université de La Réunion, Institut de Physique du Globe de Paris, Université Sorbonne Paris Cité, Saint Denis, France

\begin{abstract}
Piton de la Fournaise is one of the world's most active and visited volcanoes. Its summit crater (Cratère Dolomieu), the main tourist attraction, underwent a major caldera collapse in 2007 and its rim is not yet stabilized. In order to assess the caldera rim instability risk for visitors, we followed its structural evolution from 2007 to 2015 . Using aerial photogrammetry campaigns, we mapped the unstable sites very precisely, carried out a quantitative analysis of the temporal evolution of these instabilities, and assessed the risks for visitors. Considering the 2008-2015 period, four sites close to the crater's edge showed significant horizontal ground motion $(0.5-2 \mathrm{~m})$, fracture widening (average of $0.3-0.56 \mathrm{~m}$ ) and large-scale mass wasting volumes (total of $\left.1.8 \pm 0.1 \times 10^{6} \mathrm{~m}^{3}\right)$. We infer two different processes at work: (I) to the west and north, toppling of the basalt units occurs after periods of fracture widening due to the combined effect of magmatic intrusions and long-term inflation/deflation cycles; (2) to the south and east, parts of the caldera rim slowly slide towards the caldera centre, with significant accelerations during periods of enhanced volcanic activity (in 2008-2010 and 20I420I5). The official observation platform is the most stable zone to overlook the Cratère Dolomieu. By contrast, the most frequently visited area of the rim (northwest) outside the official platform is also the most unstable.
\end{abstract}

\section{Keywords}

Structure-from-motion, Piton de la Fournaise, caldera, mass wasting events, ground motion, risk for visitors

\section{Corresponding author:}

Allan Derrien, Observatoire Volcanologique du Piton de la Fournaise, Institut de Physique du Globe de Paris, Université Sorbonne Paris Cité, Univ. Paris Diderot, CNRS, F-974I8 La Plaine des Cafres, La Réunion, France.

Email: allan.derrien@yahoo.fr 


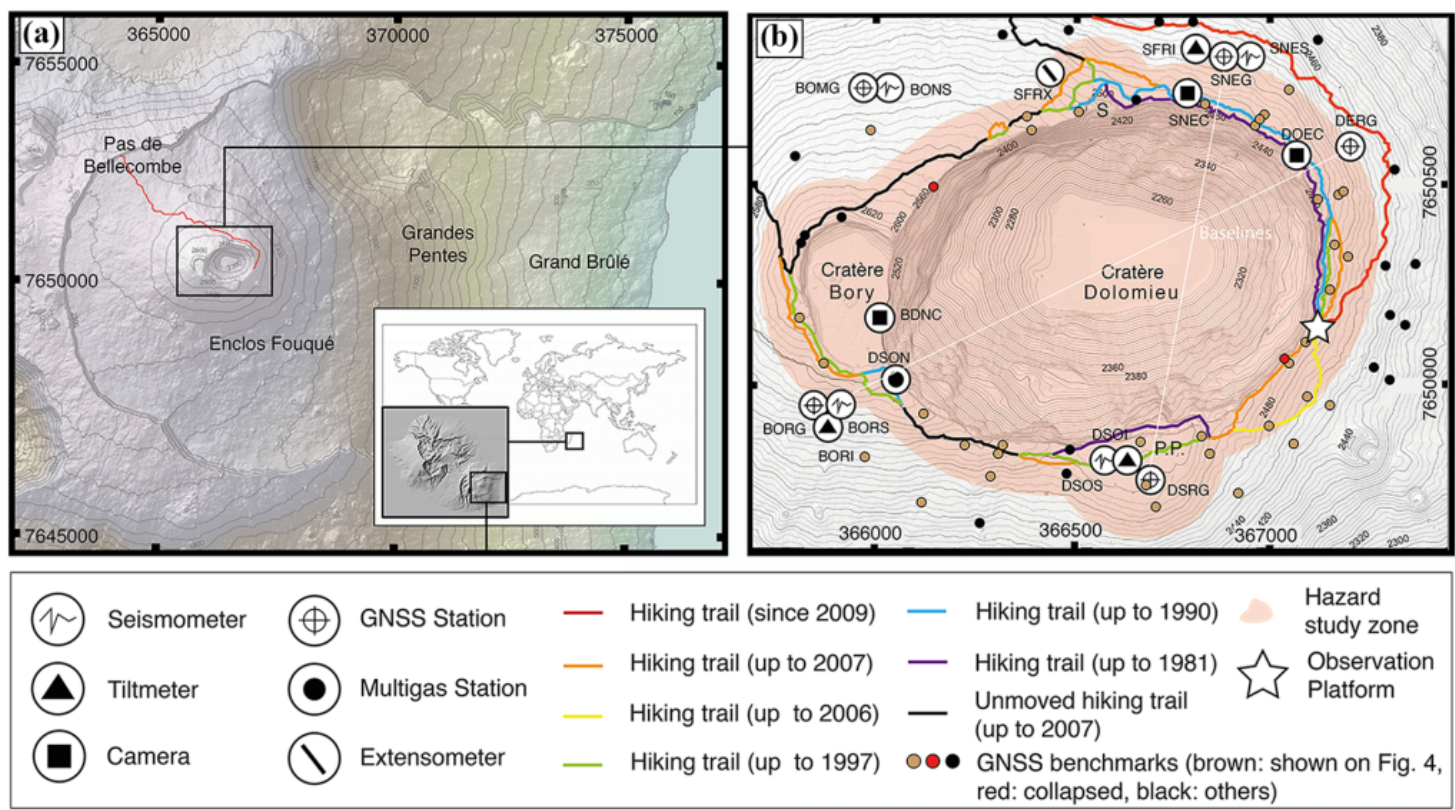

Figure I. (a) Topographic map and location of Piton de la Fournaise (PdF). (b) Map of the summit area showing the two main summit craters, the Cratère Bory and the Cratère Dolomieu, the location of monitoring stations, the successive locations of the hiking trail, the location of the current observation platform, the GNSS benchmarks used in this study and the hazard study zone. S = Soufrière pit crater. P.P. = Petit Plateau. Coordinates in meters (WGS84, UTM 40 S).

\section{Introduction}

The Piton de la Fournaise (PdF) volcano is a major tourist attraction of La Réunion (Indian Ocean, Figure 1(a)) with 129,000 hikers per year, according to Office National des Forêts (ONF), the French National Forestry Commission (Jacquard and Villeneuve, 2011), and one of the world's most active volcanoes, with a mean rate of one eruption every 5.3 months since 2014.

Until early April 2007, the Cratère Dolomieu (the $\mathrm{CD}$ ), the largest summit crater topping the terminal cone at PdF, had been filled by the accumulation of lava flows occurring during the last 72 years (Michon et al., 2013). CD deepened and enlarged during the caldera collapse that occurred in April 2007, inducing a slight increase in crater area and a drastic deepening (loss of elevation of up to $320 \mathrm{~m}$ ) (Michon et al.,
2007; Staudacher et al., 2009). This collapse occurred during a major eruption that occurred $7.5 \mathrm{~km}$ from the summit (e.g. Michon et al., 2007; Roult et al., 2012). Since then and until at least mid-2015, PdF has undergone three distinct phases of activity. (1) Between 2008 and 2010, four eruptions (September, November and December 2008, and January 2010) opened vents directly inside the $\mathrm{CD}$. In addition, two short-lived ( $<1$ day) eruptions (November and December 2009) opened vents on the caldera rim, outside the CD but close to the edge, and two eruptions (October and December 2010) opened vents on or at the base of the central cone slopes. This was accompanied by intrusiononly events (i.e. aborted eruptions) in 8 and 12 September and 20 and 31 October 2008, 7 and 18 October 2009 and 23 September 2010 (Roult et al., 2012). During the inter-eruptive phases of this period, the summit mainly 
deflated slowly. However, the successive dyke injections resulted in a rapid summit inflation over the 2008-2010 period. (2) Between 2011 and 2014, the volcano did not produce any eruptions and slowly deflated. (3) Between mid-2014 and mid-2015, three eruptions (June 2014, February and May 2015) opened vents on the rim close to the edge of the CD (for the two former) and further down the central cone (for the latter). Unlike 2008-2014, during the inter-eruptive phases of 2014-2015 the summit was continuously inflating.

As on many unstable calderas (e.g. McGuire, 1996; Merle et al., 2008), the rim of the CD is still not stabilized and is regularly subjected to toppling or sliding (e.g. Hibert et al., 2014). Initially, access to the summit was strictly forbidden after the 2007 collapse event. On 24 December 2009, the authorities reopened the summit with a new hiking trail leading to the eastern part of the caldera (Figure 1(b)). This new official track keeps visitors more than $180 \mathrm{~m}$ away from the caldera depression and leads up to a natural stable platform selected by the Observatoire Volcanologique du Piton de la Fournaise (OVPF), the BRGM (Bureau de Recherches Géologiques et Minières: the Geological and Mining Research Bureau), the ONF and the National Park. Nevertheless, the former hiking path running along the unstable crater's edge is still regularly used by mountaineering guides with tourists, unaccompanied visitors or scientific teams that are then exposed to a high risk of falling (Figure 2). Regarding the infrastructure, eleven permanent stations of the OVPF are installed close to the unstable caldera rim (Figure 1(b)).

Although various risks linked to PdF volcanic activity have been addressed (e.g. Michon et al., 2013; Peltier et al., 2012; Stieltjes and Moutou, 1989; Villeneuve and Bachèlery, 2006), no study has been made of the relationship between instability hazard and visitor presence at the summit. Yet this risk does exist. Several deadly falls at the summit and on the
Enclos Fouqué caldera rim have been reported in the local press, even before the April 2007 collapse.

The major April 2007 collapse (i) significantly increased the depth of the caldera, (ii) destabilized the edges of the summit, (iii) changed the consideration of this risk for visitors and authorities and, as a consequence, (iv) confined visitors to a less impressive but safer trail to reach the summit.

We aim to evaluate the potential risks encountered at the summit since the collapse, using structure-from-motion (SfM). SfM enabled us to (1) map ground motion around the caldera's rim with decimetre precision, (2) map the fracture width around the caldera and (3) measure the volumes of collapsed material inside the CD. Data produced from SfM was corroborated by regular GNSS (global navigation satellite system) measurements made on benchmarks around the $\mathrm{CD}$ and by rock-fall detection from seismic signals.

\section{Methods}

\section{Ground displacements and rock-fall budget}

I.I Multi-temporal SFM. SfM allows the reconstruction of three-dimensional (3D) digital models from multiple photographs (e.g. Koenderink and Van Doorn 1991; Turner et al., 2012). We analysed digital images of the summit to explore two parameters: (1) surface processes, including ground motion, fracture widening, retrogressive erosion of the rim, and (2) mass wasting balance inside the caldera. We used seven aerial photographic sets, taken between April 2007 and May 2015. Photographs were acquired from a light airplane with hand-held cameras (see details in Table 1 and Annex 2 of the Appendix; full PhotoScan reports are available online in Derrien and Villeneuve, 2018). Each photograph dataset was processed with Agisoft PhotoScan Pro (v.1.2.3) SfM software (e.g. Bolognesi et al., 

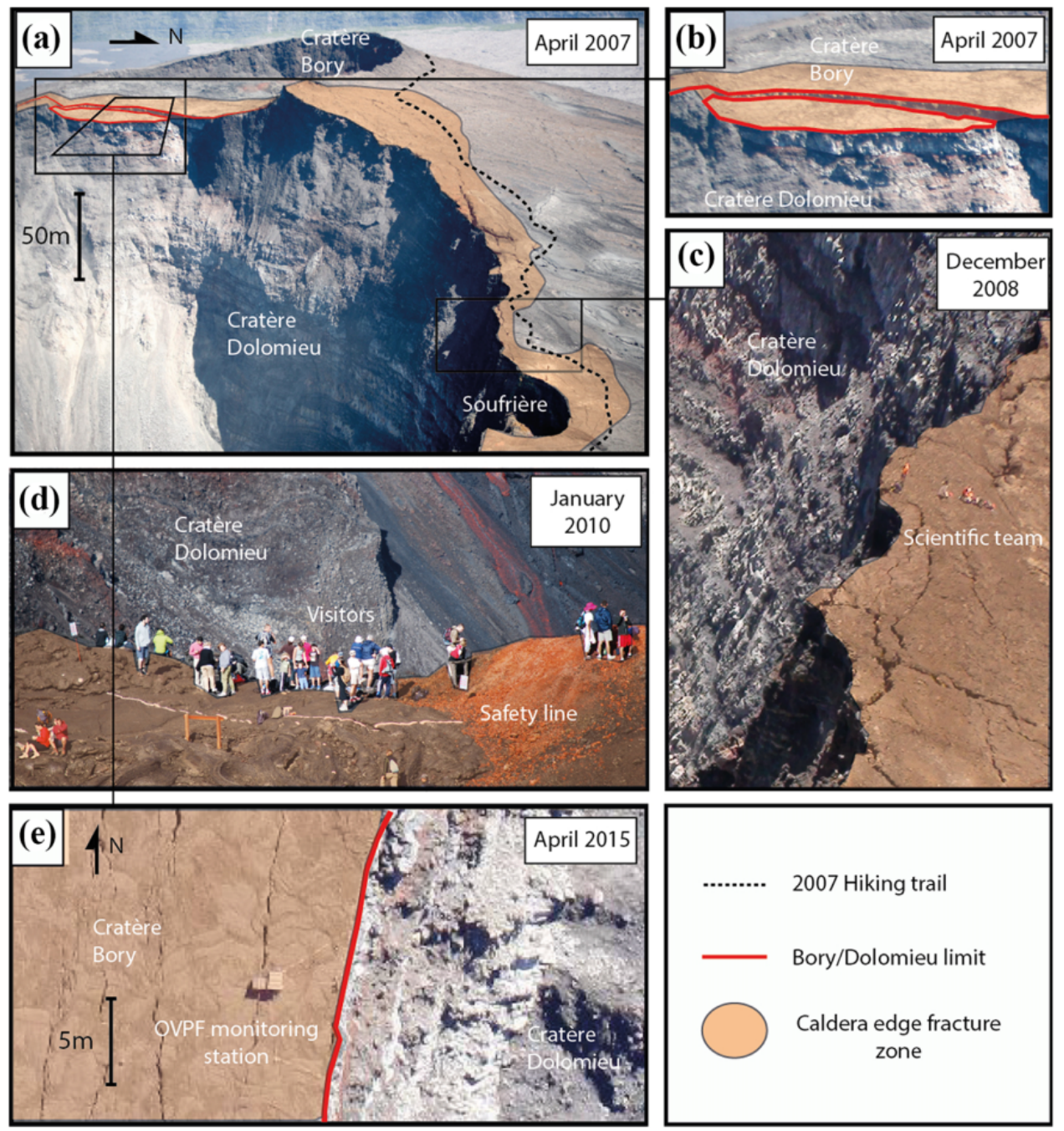

Figure 2. (a, b) Aerial oblique views of the summit in 2007 from the east, showing a fractured area near the western and northern parts of the Cratère Dolomieu's rim and the hiking trail as it was until the 2007 collapse. (c) Aerial oblique view of the north-western part of the rim in October 2008. (d) Aerial oblique view of the eastern observation platform. (e) Aerial vertical view of the limit between the Cratère Dolomieu and the Cratère Bory in 2015 (north up).

2015) in order to retrieve high-resolution digital elevation models (DEMs, 0.45-1.17 m resolution) and orthorectified images (ortho-images, $0.1 \mathrm{~m}$ resolution).

Georeferencing was carried out by measuring of the X, Y and Z positions (UTM WGS 1984, zone $40 \mathrm{~S}$ ) of targets visible on aerial images (Table 1 or else see the PhotoScan reports available in Derrien and Villeneuve, 2018). Measurements were done in the field with GNSS method (direct georeferencing) or on DEM and ortho-image combinations (digital georeferencing) with GIS (geographic information system). Two models were directly georeferenced (April 2008 and April 2015) for high-precision comparison (see Figure 4). 
Table I. Details of the aerial SfM surveys carried out during the study period and post-processing results. 'Direct' means that GCP position was measured on-field with GNSS receivers, while 'Digital' means that GCP position was retrieved from GIS computer measurements on ortho-image/DEM combination. Full PhotoScan reports of the different projects can be found in Derrien and Villeneuve (2018).

\begin{tabular}{lcclcccccc}
\hline & & & & \multicolumn{2}{c}{ Resolution $(\mathrm{m})$} & & & \\
\cline { 5 - 7 } Date & Photos & Focal length $(\mathrm{mm})$ & Camera & Ortho-image & DEM & GCP & Type & Error \\
\hline $04 / 19 / 07$ & 147 & $20-70$ & DI00 & 0.29 & 1.17 & 6 & Digital & 3.01 \\
$04 / 12 / 08$ & 50 & 45 & Mamya Phase I & 0.13 & 0.49 & 39 & Direct & 0.52 \\
$10 / 04 / 08$ & 187 & $24-28$ & EOS-ID Mark III & 0.16 & 0.66 & 8 & Digital & 0.98 \\
$12 / 18 / 09$ & 112 & 24 & EOS-ID Mark III & 0.26 & 1.04 & 27 & Digital & 0.7 \\
$12 / 12 / 14$ & 194 & 35 & EOS-ID Mark III & 0.13 & 0.55 & 44 & Digital & 0.95 \\
$04 / 07 / 15$ & 488 & 35 & EOS-ID Mark III & 0.11 & 0.45 & 61 & Direct & 0.24 \\
$05 / 23 / 15$ & 696 & 35 & EOS-ID Mark III & 0.19 & 0.74 & 76 & Direct & 0.5 \\
\hline
\end{tabular}

Indeed, it is important to consider that direct georeferencing gives more accurate results; $X$, $\mathrm{Y}$ and $\mathrm{Z}$ positions input into the process are true positions at the time of the GNSS survey. On the contrary, digitally retrieved $\mathrm{X}, \mathrm{Y}, \mathrm{Z}$ positions are sometimes slightly offset from the true position of the target at the time of survey because of summit deformation $(0-50 \mathrm{~cm})$, giving somewhat less accurate results. The April 2007, October 2008, December 2009, December 2014 and May 2015 models were digitally georeferenced using the April 2008 and April 2015 models.

In order to achieve high resolution mapping ( $1 \mathrm{~m}$ ) of horizontal ground motion, we applied a two-dimensional (2D) cross-correlation algorithm (CIAS, correlation image analysis software; e.g. Heid and Kääb, 2012; Derrien et al., 2015) to the April 2008 and April 2015 georeferenced ortho-images (Figure 3(c)). Studies show that CIAS can be trusted to evidence shifts of 0.25-0.7 pixels and above (e.g. Kääb and Leprince, 2014).

The evolution of tangential fracture width at the summit is also a good indicator to characterize the crater stability. We measured fracture width by using natural targets (identifiable blocks) located close to and on both sides of the fractures and drawing a transect roughly perpendicular to the fracture. Twenty-eight fractures were mapped in the different surveys (Figures 3(d), 4 and 5). Retrogressive erosion was also followed by digital measurements on successive ortho-images (Figure 3(a)). The mass wasting budget and mapping was obtained by subtracting DEMs (difference of DEMs, or DoD, approach) and integrating surface difference over areas of elevation change (e.g. Figure 3(b)).

I.2 Data combination. To ensure the reliability of the results, SfM reconstruction and crosscorrelation results were compared with measurements carried out on a specific, repeatedly surveyed GNSS network composed of about 60 benchmarks (Figure 4).

Furthermore, four OVPF permanent GNSS stations (Figure 1(b)) provided two perpendicular baselines crossing the summit. The baseline evolution enabled us to estimate the impact of edifice inflation/deflation on instabilities.

The three OVPF seismic stations located close to the summit (Figure 1(b)) provided the daily number of rock-fall events. We compared the mass wasting volume deduced from SfM to the number of seismically determined rock-falls for a given period to estimate the average size of rock-falls. 

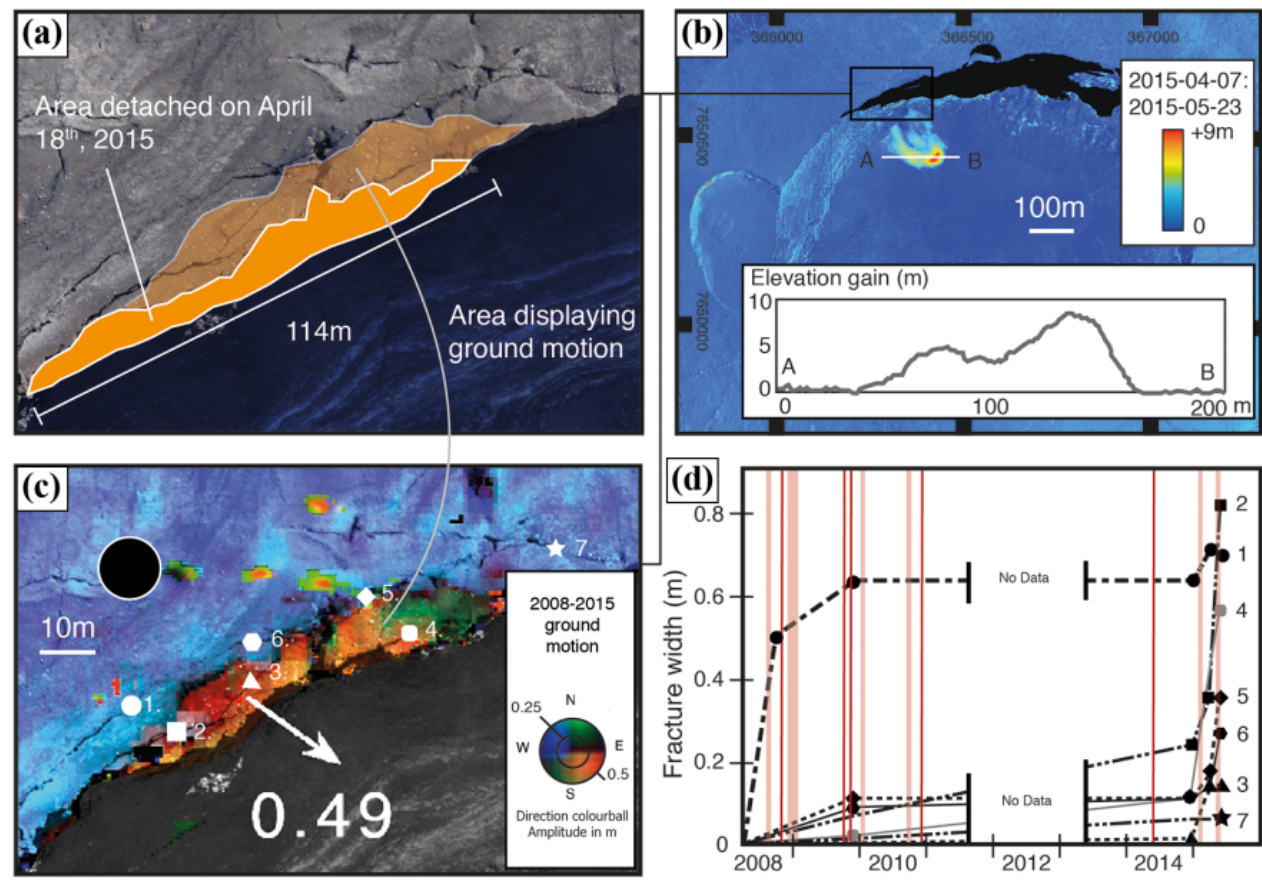

Figure 3. (a) Receding of the edge from comparison of ortho-images (7 April and 23 May 20I5) after the 18 April 2015 landslide inside the Cratère Dolomieu caldera. (b) Elevation difference between 7 April and 23 May 2015, showing the deposit at the bottom of the 18 April landslide (in black, no data). (c) Surrounding ground motion (I 2 April 2008-7 April 20I5) preceding the event at this site, as represented in the colour ball. The vector (arrow) represents the motion in relation to the black dot. The white dots localize the different fractures, whose width evolution is shown in (d). In grey tones, no data. (d) Surrounding fracture width evolution between April 2008 and May 2015, as localized on (c) by small white dots, inferred from the successive ortho-images. Red shaded areas represent eruptive periods. Coordinates in meters (WGS84, UTM 40 S).

\section{Societal approach}

We evaluated the visitor-preferred locations on the different rim sectors, following four guidelines: (1) OVPF's team members, who very often visit the summit, were interviewed by the authors. They were asked whether they met hikers off tracks or near the summit crater edges. This gives a very qualitative view of the subject. (2) Between January and June 2008, a period during which access to summit was officially forbidden, a survey was conducted to count and locate 'illegal' hikers on the volcano (Jacquard, 2009; Jacquard and Villeneuve, 2011). (3) During the same period, a series of interviews enabled us to analyse the hiker motivation for walking on the forbidden path (Morin et al., 2010). (4) In 2015, mountaineering guides were interviewed by the authors to have an overview of the number, preferred locations and motivations of hikers outside the official track.

\section{Results}

I Surface processes: retrogressive erosion, ground motion and fracture evolution on the caldera rim

Significant changes of the caldera rim between April 2008 and April 2015 were evidenced from 


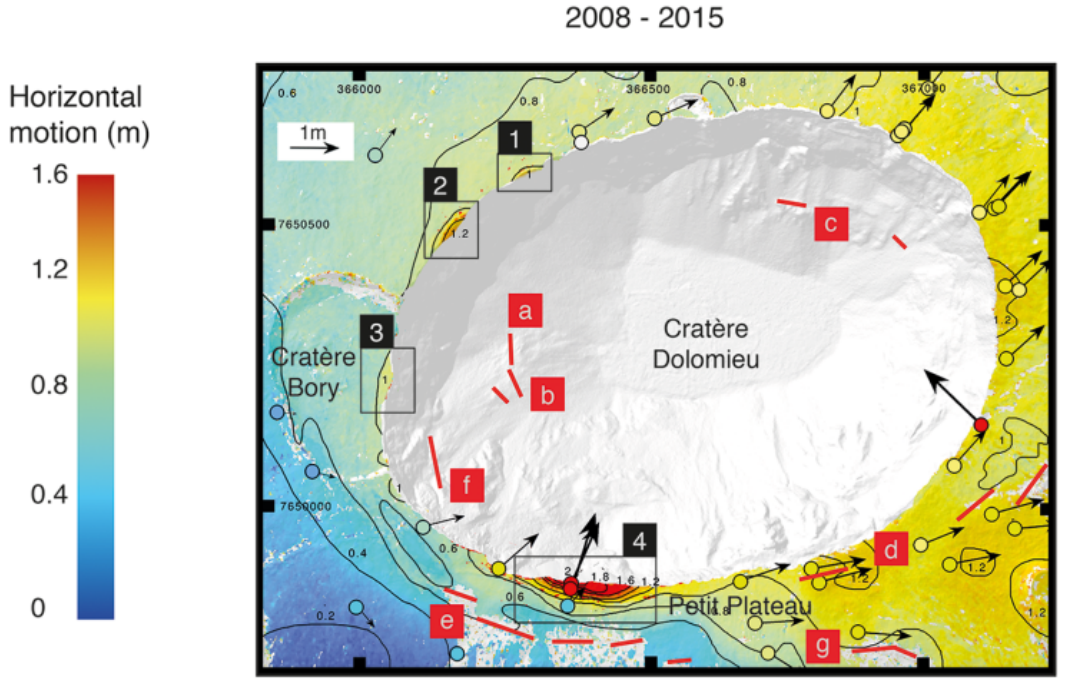

Figure 4. Ground motion map. Amplitude contour lines and colour map of movement obtained by image cross-correlation between the April 2008 and April 2015 ortho-images, and comparison with the amplitude of the movement measured on benchmarks by GNSS (dots and vectors represent the horizontal ground motion, the colours scale of the dots is the same as the one used for the cross-correlation results, see colour bar). The boxes highlight the areas of the rim moving towards the centre of the Cratère Dolomieu, which are shown in Figure 5. Eruptive fissures are noted as follows: (a): 2008/09/2 I, (b): 2008/I I/27, (c): 2008/I2/I5, (d): 2009/I I/ 05, (e): 2009/I2/14, (f): 2010/0I/02, (g): 2014/06/2I. Coordinates in meters (WGSa84, UTM 40 S).

the ortho-images. The edge receded between 2.5 $\mathrm{m}$ and $22.1 \mathrm{~m}$ after the fall of rock units in specific sites (for details, see Annex 1 in the Appendix). Seven out of the eight largest rock-falls occurred in the western half of the rim, and four out of these seven in the northwestern quarter.

In order to check the quality of the SfMderived ground motion map, we compared ground displacement values estimated by image cross-correlations between 2008 and 2015 with those measured by GNSS (Figure 4). Annex 3 of the Appendix presents clear evidence that motion measured on the SfM-derived orthoimages is highly consistent with GNSS data. Ground motion was slightly overestimated on image analysis measurements in two areas on the edges of the models (overestimates of 10-20 $\mathrm{cm}$ in the easternmost and westernmost parts of the summit). Other areas had lower differences between GNSS and SfM-derived estimates, ranging between 5 and $10 \mathrm{~cm}$. This is symptomatic of a general lens distortion caused by PhotoScan processing (also called 'barrel' effect). Barrel distortion accounts for $0.03 \%$ of the model size. For instance, a deformation affecting a $200 \mathrm{~m}$-wide site could be underestimated by $7 \mathrm{~cm}$.

The ground displacements at the summit scale $(1-1.5 \mathrm{~km})$ showed a first order general motion of the summit with the highest displacement values, mainly oriented eastward, consistent with other studies (Figure 4; Derrien et al., 2015; Got et al., 2013; Peltier et al., 2007). The south and north sections showed smaller magnitude southward and northward motion. The western part was less affected by significant horizontal ground motion.

SfM showed a second-order deformation in four sites, defined as sites 1, 2, 3 and 4 (Figure 4). These sites were already identified using GNSS measurements after the April 2007 

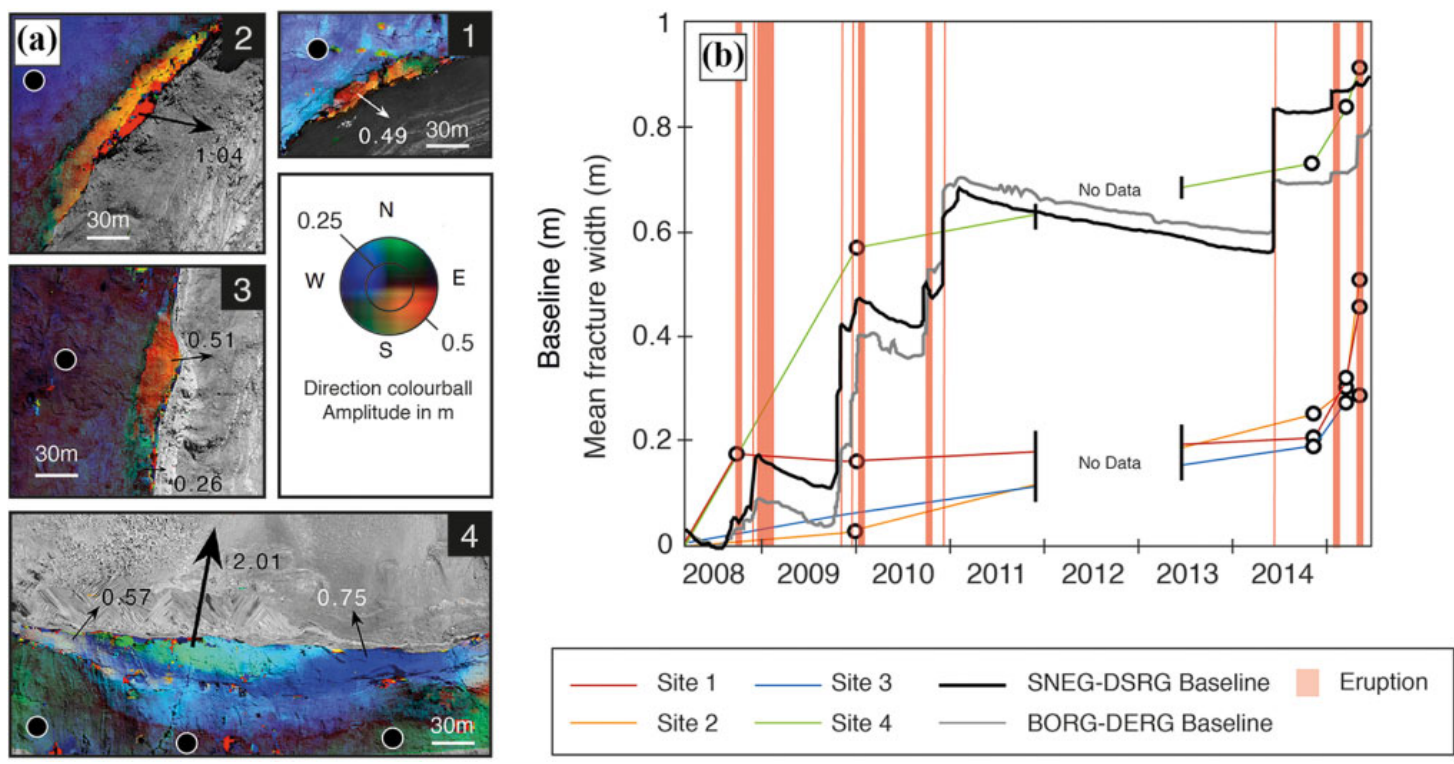

Figure 5. Close-ups of the most unstable zones of the Cratère Dolomieu's rim. (a) The colours represent the direction and amplitude (symbolized in the colour ball) of movement between 2008 and 20I5, while the arrows show the horizontal motion (in meters) of the unstable zones relatively to the stable ground localised by black dots. The areas with no data are in greyscale. (b) Evolution of mean fracture width (average of 7 fractures) of each site shown in (a) (coloured lines) and evolution of distance change between permanent GNSS stations (baselines shown in Figure I(b)), DSRG-SNEG (black solid line) and BORG-DERG (grey solid line). See Figure I for localization of these stations. Note the increased fracture opening in site I between 2007 and 2009 (compared to sites 2 and 3): one of the seven measured fractures opened abnormally fast during this period and thus increases the computed mean fracture width. It is thus not representative of the behaviour of this unit. Red shaded areas represent eruptive periods.

caldera collapse (Michon et al., 2009), and our data confirms the persistence of this motion in and after 2008. Each of these sites showed displacements toward the centre of the caldera.

We applied a correction to the displacements for these four sites by subtracting the first order offset value characteristic of the proximal zone unaffected by second order displacement (black circles; Figures 3(c) and 5(a)). This correction of the geodynamic and volcanological background signature made it possible to highlight the specific displacement of the four sites (arrows in Figure 5(a)). We measured centripetal shifts of up to $0.49 \mathrm{~m}, 1.04 \mathrm{~m}, 0.51 \mathrm{~m}$ and $2.01 \mathrm{~m}$ between 2008 and 2015 on sites 1, 2, 3 and 4 , respectively. These movements covered arcuate areas of $107 \times 15 \mathrm{~m}, 233 \times 28 \mathrm{~m}, 122 \times$
$29 \mathrm{~m}$ and $316 \times 71 \mathrm{~m}$ (maximum length and width) for sites 1, 2, 3 and 4, respectively. The stable part of the summit was delineated by one or more tangential fractures.

The average fracture width bordering the moving zones increased faster after December 2014, especially for sites 1 and 2 (Figures 4 and 5 (a)). There, $52 \%$ and $54 \%$ (respectively) of the total widening observed between 2008 and 2015 occurred in only 5 months, between December 2014 and May 2015 (Figures 3(d) and 5(b)). A large mass wasting event of $47.8 \pm 3.6 \times 10^{3} \mathrm{~m}^{3}$ was recorded on 18 April 2015 on site 1, coeval with a receding of the edge by a maximum of $12 \mathrm{~m}$ on a $114 \mathrm{~m}$ long segment (Figure 3(a) and (b)). The area affected by ground motion extended outward over a distance of $10-15 \mathrm{~m}$ 
from the caldera edge. A similar deformation, with lower intensity was also recorded near the Cratère Bory (CB) (site 3 in Figure 5(a)). There, $32 \%$ of the total widening observed between 2008 and 2015 occurred between December 2014 and May 2015.

To the south (site 4), different movements were observed. Most of the widening (65\%) between 2008 and 2015 occurred between April 2008 and December 2009, while only $9 \%$ occurred between December 2009 and December 2014. Fracture widening accelerated again after December 2014 (26\% of the total opening occurred between December 2014 and May 2015).

\section{Mass-wasting budget inside the caldera}

Mass wasting events inside the caldera were mapped for different periods in order to quantify both their spatial and temporal evolution (Figure 6; note that volume value can, in some cases, represent a succession of small events instead of one big event). Due to the precision of the method, we only considered volume differences between two SfM campaigns larger than $1000 \mathrm{~m}^{3}$ (resulting from one single or several mass wasting events). We determined cumulative mass wasting volume inside the caldera of $4.2 \pm 0.5 \times 10^{6} \mathrm{~m}^{3}$ and $1.8 \pm 0.1 \times 10^{6} \mathrm{~m}^{3}$ between April 2007 and April 2008, and between April 2008 and May 2015, respectively (Figure 6 ). Note that the errors result from global and conservative uncertainty in the georeferenced models (Table 1). This uncertainty was multiplied by the area affected by rock-falls to obtain the volume confidence intervals. Since these reconstructed errors (mainly distortions and barrel effect) can vary spatially, one could argue that this is only an indicative assessment of the confidence we have in the computed volumes. For each mass wasting event, we checked manually that the models were correctly co-referenced in the vicinity of the event. To do this, we used the zones of no change (we knew there had been no change because the ortho-images were exactly

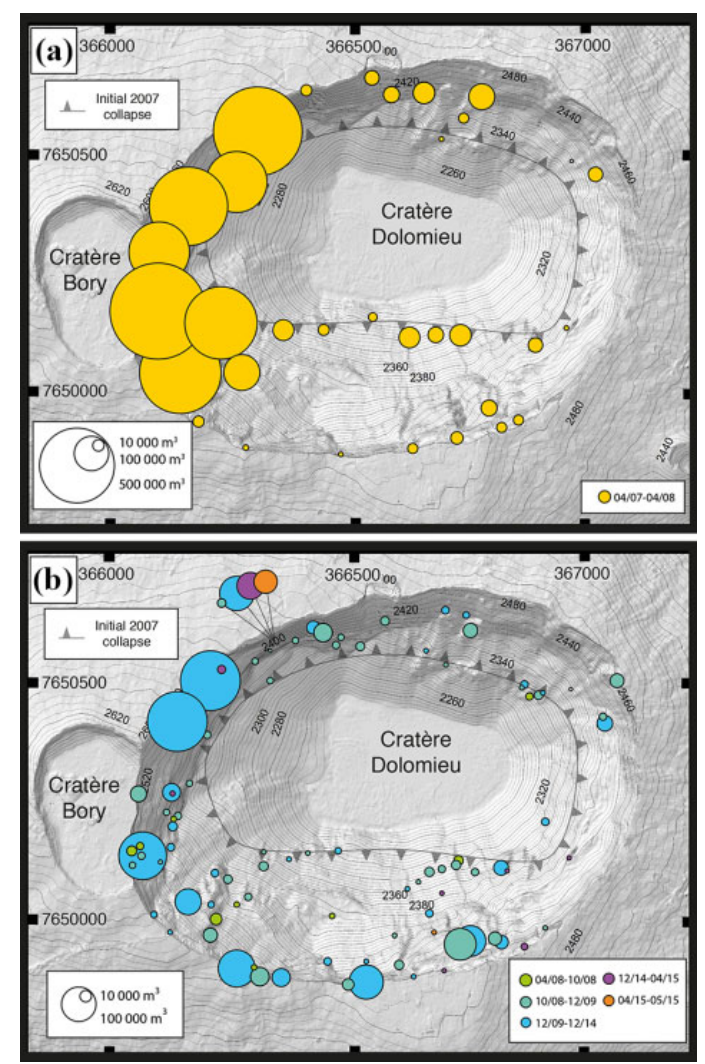

Figure 6. Volume and location of mass wasting events inside the Cratère Dolomieu, as measured from DEMs differences, between (a) April 2007 and April 2008 and (b) April 2008 and May 2015. The colours represent the different periods. Coordinates in meters (WGS84, UTM 40 S).

the same in these zones, and pure vertical motion had not occurred, except at the foot of the CD, which is not studied here because regularly covered by new lava flows). If this was not the case (not correctly co-referenced), we corrected the measurements accordingly.

This cumulative mass wasting volume gave a yearly mean mass wasting rate about 16 times less after April 2008 than during the first year after the April 2007 collapse. Figure 6 clearly shows that the most unstable areas were in the western and north-western parts of the CD: $44.7 \%$ of the volume collapsed in the northwest and $39.9 \%$ in the west between 2008 and 2015 . 

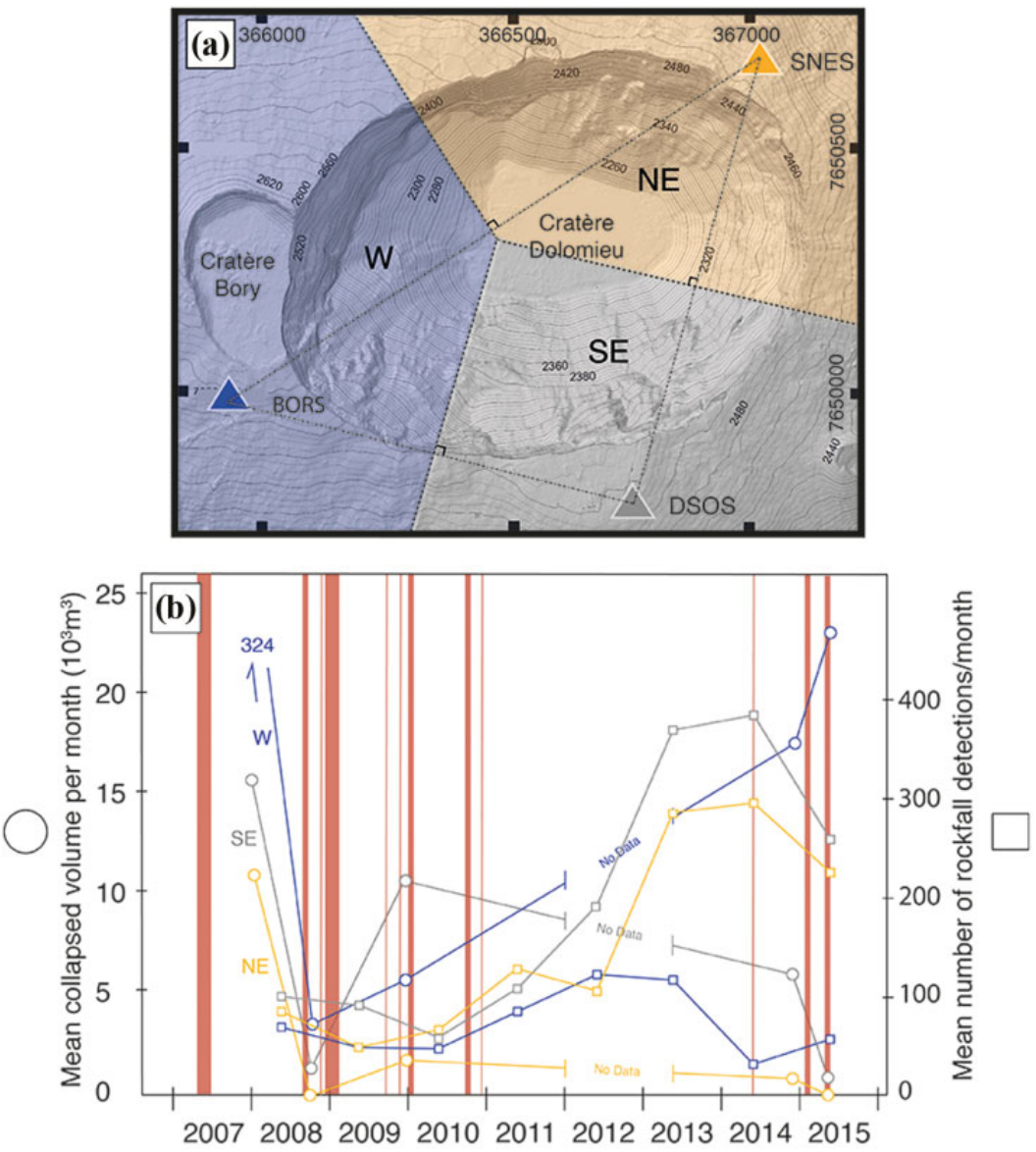

Figure 7. Zones by mass wasting event characteristics observed between April 2008 and May 20I5. (a) Map showing the three sites considered (west, southeast and northeast). (b) Average collapsed volume per month and per site (lines) and cumulative number of events detected per seismic station (coloured shaded areas; for each site, we counted the events whose seismic wave first reached the station located in the site). Volumes are inferred from aerial surveys, which were conducted at irregular intervals. Thus, each value is an average, representative of the preceding period. Red shaded areas represent eruptive periods.

Caldera rim destabilizations decreased toward the east where only few SfM-detectable mass wasting events were observed. However, very small events were detected in the east and south using the seismic network (Figure 7).

Considering the location of the three closest seismic stations (closest to the caldera), we chose to divide the summit into three parts (W, NE and SE - Figure 7(a)) to improve spatio-temporal analysis of the rock-fall and mass wasting events.
We determined a significant decrease of mass wasting rates for all three parts during the first year after the collapse (Figure 7(b)). The temporal trends deduced from SfM suggest that the mass wasting rates then increased for all three areas between October 2008 and December 2009. This evolution then stopped in the SE and NE sections, while these rates were still increasing in the western section. The difference between the April and May 2015 DEMs revealed a large volume of material $(47.8 \pm 3.6$ 
$\times 10^{3} \mathrm{~m}^{3}$ ) deposited at the foot of the northwestern cliff. The western and north-western sections of the caldera had fewer but significantly larger mass wasting events than the other areas (Figures 6 and 7(b)).

We analysed the number of destabilization events detected by the seismic stations, each event being counted only once, at the BORS, SNES and DSOS station receiving the signal first (Figure 7). Three main periods can be distinguished (Figure 7(b)). Between 2008 and 2009 , the average number of detections per month remained more or less around 100 for all three sectors, with only a slight decrease. Between 2010 and 2013, the number increased to 300-400 detections/month for the NE and SE. This increase was coeval with a decrease in average volume/month in the NE and SE. Opposite behaviour was observed for the $\mathrm{W}$ section, where both the mean number of detections/month and the mean volume/month significantly increased. Finally, between 2014 and 2015 , the mean volume/month decreased in the $\mathrm{NE}$ and SE, increased in the $\mathrm{W}$, while the mean number of detections/month decreased slightly.

\section{Exposure to hazard for visitors}

Considering the caldera rim instability, it is important to assess the exposure to this hazard for visitors, and in particular estimate the number of visitors at the different caldera rim sites. In 2011, 129,000 hikers accessed the summit (Jacquard and Villeneuve, 2011). A survey of visitors carried out in 2008 (Jacquard, 2009; Jacquard and Villeneuve, 2011) enabled the mapping of tourist attendance on the $\mathrm{CD}$ rim at the time when access was prohibited. For a sample of 126 persons interviewed, the highest parts of the $\mathrm{CD}$ rim, north and south of the $\mathrm{CB}$ were the most attractive parts of the summit, with $54 \%$ of the visitors in 2008 (Figure 8). The $\mathrm{CB}$ and the track surrounding it attracted $15 \%$ of the visitors, while only $4 \%$ of the visitors went to the eastern part of the $\mathrm{CD}$ rim. Overall, for the entire rim, $76.2 \%$ of the interviewees came within $2 \mathrm{~m}$ of the edge, while only $2.4 \%$ stayed on the former track (Figures 1(b) and 8(a)). Another survey of CD rim visitors, including estimations by mountaineering guide agencies and field agents, was carried out in 2015 . According to this study, the most visited area for the population hiking outside the official track was the NW section between the CB and the Soufrière (about 70-90\%), followed by the Soufrière area (about 10-15\%). The rest of the caldera rim, except for the official platform, was visited by less than $5 \%$ of visitors.

\section{Discussion}

\section{Temporal evolution of caldera rim instability}

After evidencing significant ground motion towards the centre of $C D$ at sites $1-4$, we compared our results with existing literature, describing, notably, the rim ground motion before the study, between 2007 and 2008. On 6 April 2007 (about $12 \mathrm{~h}$ after the start of the collapse), the first pictures of the collapse showed a large depression in the $\mathrm{N}$ and $\mathrm{W}$ parts of the CD (Michon et al., 2007). At that time, the pre-April $2007 \mathrm{CD}$ floor was still in place in the $\mathrm{S}$ and the $\mathrm{CB}$ was intact. After 5 days of successive collapses (5-10 April), a depression of $320 \pm 20 \mathrm{~m}$ in depth formed, with residual eastern and southern platforms gradually tilting downwards towards the caldera centre (Michon et al., 2007). Using specific GNSS measurements in 2007, Michon et al. (2009) and Peltier et al. (2009) showed that most of the deflation observed around the rim during the March-May 2007 syn-eruptive period was a consequence of the caldera collapse. The largest horizontal displacement $(2.53 \mathrm{~m})$ was located on the southern caldera rim. Moreover, the magnitude of horizontal displacements rapidly decreased away from the edge ( $-38 \%$ to $-61 \%$ of displacement in the two hundred meters closest to the edge; Michon et al., 2009). Summit deformation 
Hazards

2008-2015

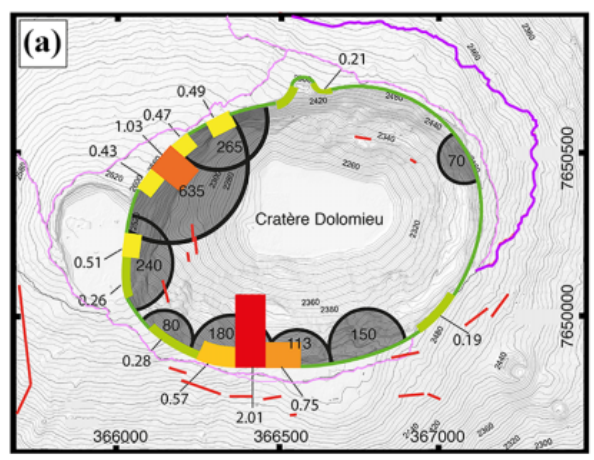

Exposures*

$2008=>2015$

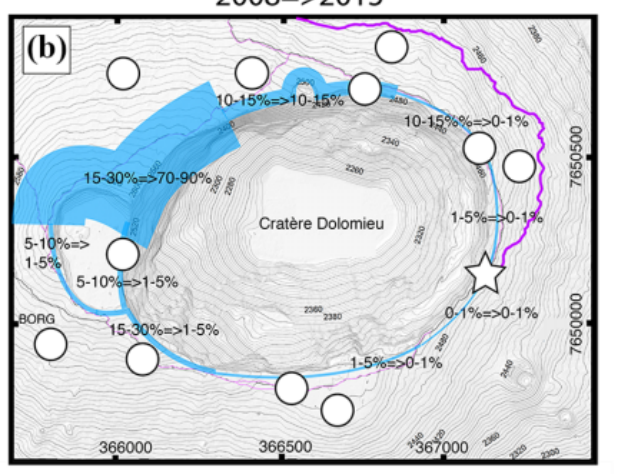

Fall due to rim instability risk index*

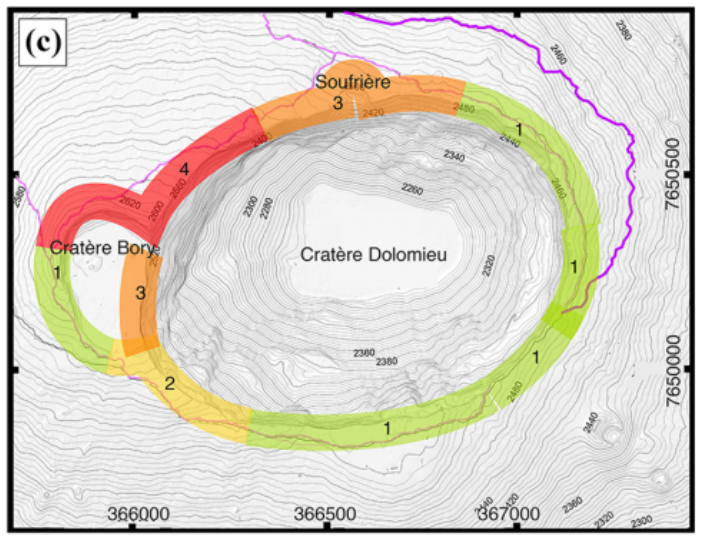

Hazards

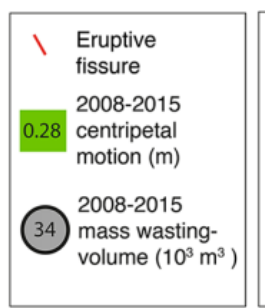

Exposures

\begin{tabular}{|l|l|}
$7.1 \%=>10 \%$ & $\begin{array}{l}\text { Percentage of hikers on the area* } \\
\text { (in 2008 } \Rightarrow \text { in 2015) } \\
\text { "outside the official trail and } \\
\text { observation platform }\end{array}$ \\
- new official trail & $\begin{array}{l}\text { OVPF Permanent } \\
\text { Station } \\
\text { Observation }\end{array}$ \\
old trail & Platform
\end{tabular}

Figure 8. Determination of the rim destabilization risk. All the maps have been synthesized to produce a classification of risk in 2015 (concerning the population hiking around the summit only: note that this figure does not represent the population using the official trail and observation platform). On the index map, level I (in green) corresponds to areas with less than $1 \%$ frequentation or less than $0.1 \mathrm{~m}$ deformation (between April 2008 and April 20I5). Level 2 (yellow) corresponds to areas with between I and $5 \%$ of visitors and between 0.1 and $0.5 \mathrm{~m}$ surface deformation (between April 2008 and April 2015). Level 3 (orange) corresponds to areas with between 5 and $15 \%$ of visitors and $0.1-0.5 \mathrm{~m}$ deformation or with between $I$ and $5 \%$ of visitors and $0.5-I$ m surface deformation (between April 2008 and April 2015). Finally, Level 4 (red) corresponds to the area with more than $50 \%$ of visitors and more than I m deformation (between April 2008 and April 20I5).

continued after the collapse. Between May and November 2007, the largest displacements were observed in the SW $(0.39 \mathrm{~m})$ and NW $(0.47 \mathrm{~m})$, suggesting either a deflation source located under the western part of the caldera and/or local deformation. The four sites identified by SfM (Figures 4 and 5) match the shape, extent and ground motion described for this postcollapse period (Michon et al., 2009).

Our DEMs revealed that mass wasting events were concentrated on the western part of the caldera between April 2007 and April 2008 (Figure 6), confirming that in the months following the April 2007 eruption the western part of the caldera rim was very unstable compared to the eastern half. The reader is referred to Staudacher et al. (2009) for a detailed and very clear description of this event.

The eastward-preferential extension of the summit observed between 2008 and 2015 (Figure 4) was mostly the consequence of the endogenous growth of the edifice. On PdF, 
dykes intrude into the central cone during summit and sometimes flank eruptions, mostly in the N-S direction (following the main rift zones). The resulting effect is that the summit zone tends to inflate more in the E-W direction. The western flank motion is somehow blocked by the Piton des Neiges edifice (neighbouring volcano), resulting in the preferential eastward motion of the "free" eastern, seaward flank (e.g. Derrien et al., 2015; Got et al., 2013; Peltier et al., 2015). SfM measurements from processing of the available datasets are arguably less reliable (see errors associated with processing in the method section) than, for example, GNSS measurements. However, they complement it by making it possible to display a high-spatial resolution map of summit deformation instead of sparse points of information.

Superimposed onto this summit-scale pattern, sites 1, 2, 3 and 4 (already destabilised just after the caldera collapse (Michon et al., 2009)) showed distinct centripetal ground displacements and unusually high mass wasting volumes. Between 2008 and 2015, three sub-periods can be distinguished: (1) April 2007-April 2008, when several large parts of the rim fell into the caldera, (2) 2009 to October 2014, when mass wasting events remained frequent but with a stabilization and (3) after October 2014 when periods of destabilization accelerated.

\section{Mechanisms triggering instability}

Sites 1, 2 and 3 show similarities in terms of (i) shape of the area concerned by ground motion, (ii) wall morphology, (iii) distance to the inner ring fault of the caldera and (iv) temporal evolution of their fracture width.

Each of the three sites located northwest and west of the caldera appeared as structurally coherent blocks separated from the rest of the edifice by fracture zones (Figure 5(a)). Throughout the study period, they moved towards the caldera centre (Figure 5) and parts of them regularly toppled ('peeled off') from the cliff during large-scale and rapid mass wasting events (Figure $6)$. Considering the significant ground motion (0.49-1.04 $\mathrm{m}$ between 2008 and 2015) and the fracture widening rate increase in 2014-2015 on these sites (Figure 5), it is highly probable that sudden toppling of large units on the caldera's rim will keep occurring in the near future on these sites. Site 4 differed from the other ones in terms of surface area (4-10 times larger than sites 1-3), geometry (less elongation with deformation propagating further away from the caldera edge) and extent (diffuse extension zone instead of discrete fractures). Beside these structural characteristics, we observed an important increase of the fracture width in the south before 2009 (Figure 5) and larger horizontal ground motion over the 20082015 period (0.57-2.01 m; Figure 4$)$ than in the other sites. Moreover, the volume of mass wasting events inside the caldera is smaller than for the sites that present toppling. Thus, contrary to the three previous units affected by a toppling process, this southern site is gradually subsiding towards the caldera centre (Figure 9(a) and (b)). The inward subsidence is further corroborated by the partly intact remnants of pre-caldera surface material directly downhill from the south caldera edge, which might have been previously sliding inside the caldera in a similar way. We thus interpret the destabilization process of the CD southern rim as a rock slope deformation feeding debris avalanches, in the sense of Hungr et al. (2014) terminology.

\section{Influence of the pre-existing structures}

The PdF summit structure is a complex association of filled former volcanic craters, lava flows and superficial magma pockets. Some of these structures are highly fractured, due to successive inflation/deflation periods, collapse events, or hydrothermal fluid transfers. This inherited structure mechanically affects the way the caldera rim can be destabilized. Before the 2007 caldera collapse, the summit was composed of two partially filled craters: the $\mathrm{CB}$ and 

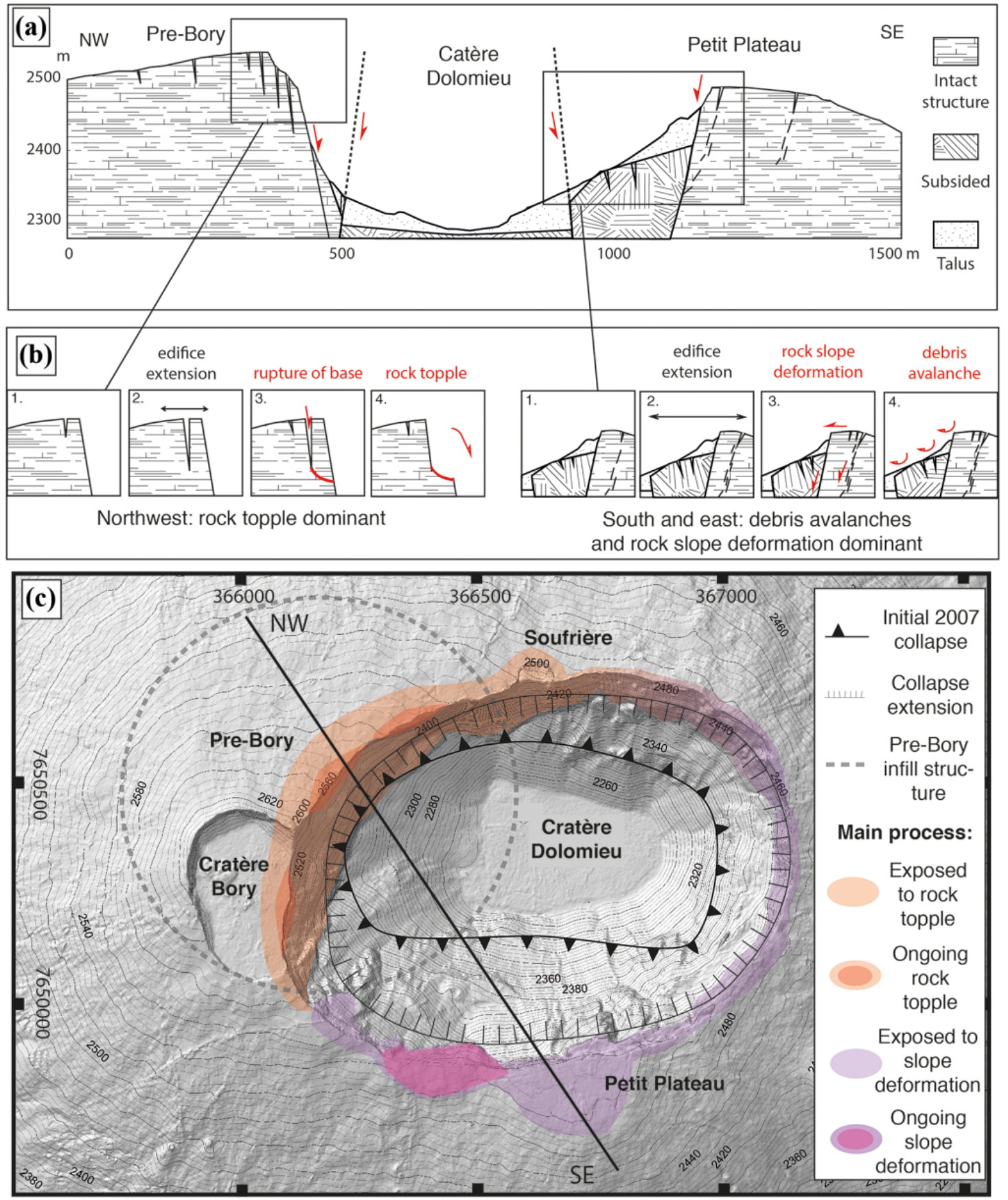

Figure 9. Structural control of instabilities around the Cratère Dolomieu. (a) Interpretative cross-section of the Cratère Dolomieu caldera along a NW-SE cross-section (see location in c). (b) Proposed mechanisms triggering instability as a consequence of summit inflation/deflation cycles. In black, volcano deformation. In red, destabilizations. (c) Map of the different mechanisms affecting caldera rim stability. Cross-section (a) is indicated by the black NW-SE line. 
the CD, consisting of several coalescent and filled pit craters aligned in the $\mathrm{E}-\mathrm{W}$ direction (Lénat and Bachèlery, 1990; Michon et al., 2013). Another main pit crater (the Pre-Bory pit crater) is visible in the CD north-western scarp, where it is filled by thick lava flows (Michon et al., 2013; Peltier et al., 2012; Figure 9(c)).

The first collapse increment of 5 April 2007 (10\% of the total $100-120 \times 10^{6} \mathrm{~m}^{3}$ collapsed volume; Michon et al., 2011) occurred in the NW part of the CD. It was accommodated by an elliptic ring fault (Figure 9). The successive collapses triggered a horizontal extension and a tilting of blocks along the S and SE rim of CD, and very steep caldera walls in the NW and N (Figure 9). The NW scarp consists of thick, homogeneous lava flows of the Pre-Bory pit crater, as opposed to the S scarp where successive lava flows are thinner and less homogeneous (Michon et al., 2013). Rock toppling occurred mainly in the NW steep wall along the caldera's inner ring fault. There, formation and widening of tangential fractures led to the decoupling of large $\left(>20,000 \mathrm{~m}^{3}\right)$ volumes eventually falling during a single event. On the contrary, in the south and the east, blocks of the caldera rim slid inwards to form diffuse extension zones at their junction with stable summit regions (Figure (a) and (b)). There, the opening of extensive tangential summit fractures accommodated extension. Note that debris avalanches close to the caldera centre (away from the edge) were concentrated along the trace of the initial collapse in the ring-fault (Figure 6).

\section{Influence of volcanic activity and other environmental phenomena}

The temporal evolution of fracture opening and mass wasting rates in sites 1, 2, 3 and 4 did not show a progressive stabilization of the caldera rim with time over the long term, as would be expected. Such stabilization occurred only during the first year after the collapse (April 2007April 2008). Then mass wasting and fracture opening rates increased between April 2008December 2009 in the SE and NE and between April 2008 and May 2015 in the NW and W (Figures 5(b) and 7(b)).

The decrease of mass wasting rates was coeval with a slowing of the summit deflation rate during a year and two months after the collapse (April 2007-July 2008). This deflation rate decrease is interpreted as resulting from the post-collapse viscoplastic volcano deformation and depressurization of the hydrothermal system (Froger et al., 2015). Then, the mass wasting rate increased in the west between October 2008 and December 2014, and accelerated even more after 2014 (Figure 7(b)). Consistently, fracture-widening rates in the northwest and west increased in the same proportions (Figure 5(b)). These sites were affected by rock topple processes (Figure 9(c)). Between 2008 and 2015, with the help of GNSS data, we were able to distinguish two periods: a summit deflation occasionally stopped before the short intrusion/ eruptions phases between 2008 and mid-2014, followed by a sharp inflation beginning in October 2014 (Figure 5(b)). The increase of the mass wasting and fracture opening rates between October 2008 and December 2014, while the summit deflated slightly, could primarily be due to discrete periods of rapid inflation and increased seismicity during the intrusive phases preceding the eruptions of that period. This effect was probably strongly reinforced after October 2014 by the near-continuous summit inflation. Inflation constantly modifies the slopes in the summit area and consequently promotes sudden destabilization events, as in site 1 between December 2014 and May 2015 (Figure 6). Overall, the signals (fracture, mass wasting volume) show that the mass wasting rates and fracture widening rates decreased by more than $50 \%$ during the one to two years after the collapse. This means that the effect of caldera subsidence lost its contribution to extension of the rim fairly quickly. After 2014, the re-activation of inward extension of the rim (as evidenced by 

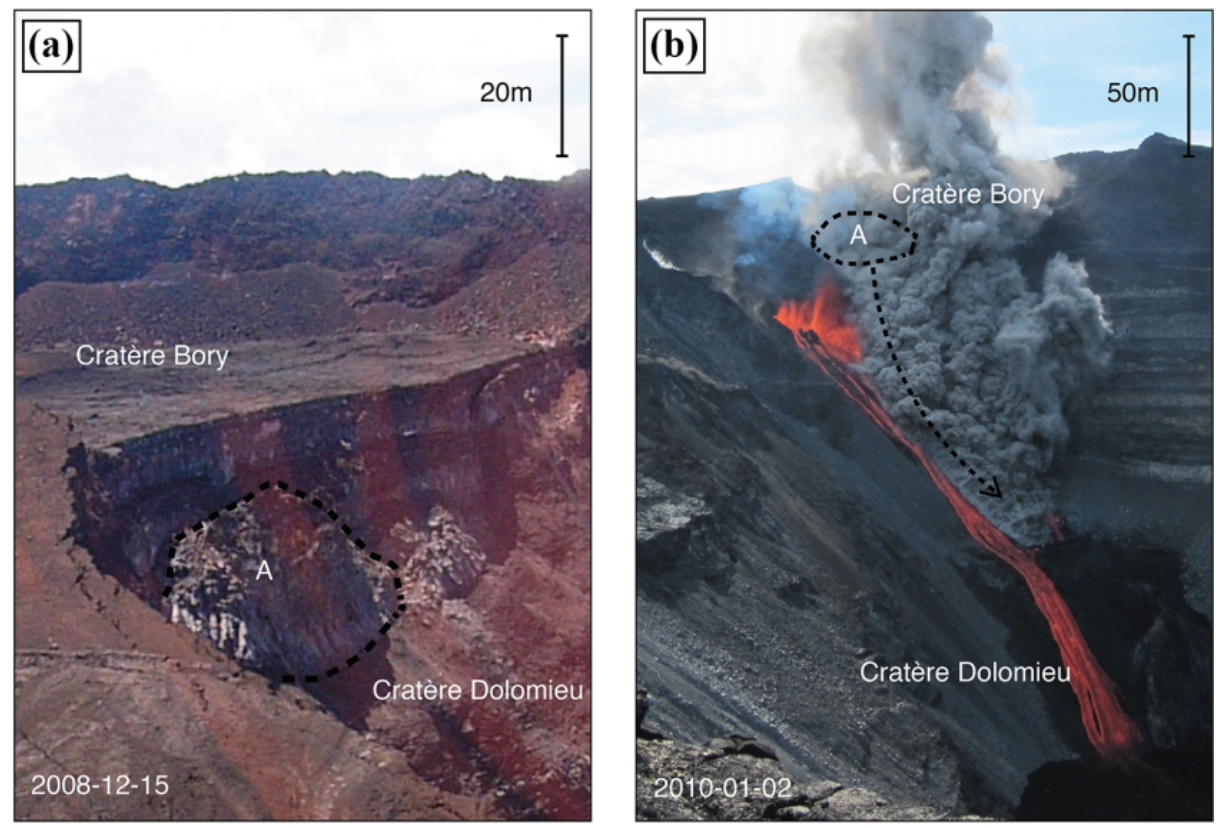

Figure 10. (a) Aerial photograph of 15 December 2008 showing the Bory/Dolomieu cliff from the south (Photo: F. Massin). Note the block in the process of detaching (A). It stayed in place until 2 January 2010. (b) Photograph showing rupture and fall of the detaching block from the southeast during the 2 January 2010 eruption inside the Cratère Dolomieu (Photo: A. Di Muro).

fracture width increase) was clearly mostly linked to the re-activation of activity and summit inflation.

We can note that eruptive fissure opening close to the caldera rim is an additional process that can trigger scarp collapses, like those observed during the first day of the January 2010 eruption that occurred at the base of the Bory-Dolomieu separating cliff (Figure 10(b)).

Finally, external factors such as rainfall and summit seismicity could also be sources of destabilization. However, because the temporal resolution of our data is very low, we did not find obvious temporal correlations between such processes. Hibert et al. (2017) showed that the systematic weight of factors such as rainfall, seismicity or local surface deformation following an eruptive fissure opening on caldera rim stability remained unclear, even with more temporally resolved data.

\section{Risk assessment}

In 2015, most visitors (between 97.5 and $99.5 \%$ according to figures from the ONF and the mountaineering guide agencies) stayed on the new hiking trail and around the observation platform in the eastern, most stable, part of the CD's rim. This indicates that the implementation of a (relatively) stable platform in 2008 was a success. Before 2008 and following the old tracks, it was common to hike around the two summit craters and more particularly to the NW of the summit, the most unstable site. Some guided tours still propose hiking around some parts of the $\mathrm{CD}$ and the $\mathrm{CB}$ (outside the official track) and it is common for the OVPF team to meet hikers in the NW part of the summit. To enable visualization of risk mapping on the caldera rim for the population of visitors leaving the new trail, we defined four levels of risk, based on the hazards and frequentation statistics 
for different areas of the summit (Figure 8(c)). Level 1 corresponds to areas with an estimation of less than $1 \%$ of visitors or less than $0.1 \mathrm{~m}$ deformation (April 2008-April 2015). Level 2 corresponds to areas with an estimation of between 1 and $5 \%$ visitors and between 0.1 and $0.5 \mathrm{~m}$ surface deformation(April 2008-April 2015). Level 3 corresponds to (1) areas with an estimation of $5-15 \%$ of visitors and $0.1-0.5$ $\mathrm{m}$ deformation or (2) with an estimation of 1$5 \%$ of visitors and $0.5-1 \mathrm{~m}$ surface deformation (April 2008-April 2015). Finally, Level 4 corresponds to the area with an estimation of more than $50 \%$ visitors and more than $1 \mathrm{~m}$ of deformation (April 2008-April 2015).

The NW part of the CD rim was the most visited area in 2008 (Jacquard, 2009) and was the most visited area outside the official track in 2015 (in this context, $86 \%$ of the visitors with guided tours, Figure $8(\mathrm{~b})$ ). This zone is particularly attractive because it stands at a higher level than the official platform, it offers a view over both craters, and it is one of the shortest walks to the summit. However, its cliffs have the highest mass wasting rate (Figure 6). Not surprisingly then, this area is categorized as risk level 4 (Figure 8(c)).

Other hazardous areas are (1) the cliff between the $\mathrm{CB}$ and the $\mathrm{CD}$ and (2) the Soufrière site (risk level 3, Figure 8(c)). Visitors using the former track occasionally go down into the $\mathrm{CB}$, which, unlike the $\mathrm{CD}$ is easily accessible. From here, they usually reach the caldera rim, in site 3 , where ground motion of up to $0.51 \mathrm{~m}$ and mean fracture opening of $0.3 \mathrm{~m}$ was recorded between April 2008 and April 2015 (Figure 8(a)). At the northern section of the $C D$, the Soufriere site is protected by a double barrier of fences. Nevertheless an estimated $10-15 \%$ of visitors walk here (Figure 8(b)). This area saw its rim recede shortly after the April 2007 collapse, but little motion has been observed since then $(0.21 \mathrm{~m}$ between April 2008 and April 2015).

In the southwest of the CD, the number of visitors decreased from $10-15 \%$ in 2008 to $1-$ $5 \%$ in 2015 . However, considering that ground motion next to the edge was $0.28 \mathrm{~m}$ between 2008 and 2015, this area has been categorized as risk level 2 (Figure 4).

Finally, the south, south-eastern, eastern and north-eastern areas received very few visitors as of 2015 (estimation around $0.1 \%$ of the visitors outside the observation platform in the east), due to their distance from the Pas de Bellecombe (Figure 1(a)). Moreover, ground motion in most of these sites did not exceed $0.19 \mathrm{~m}$ (except for the southern site) between 2008 and 2015. Thus, these sites have a risk level of 1 due to extremely low number of visitors coupled with mostly slight ground motion, the only exception being the official observation platform in the east, which is quite stable but also receives a lot of visitors.

\section{Conclusion}

Our work, based on multi-temporal SfM using high-resolution cameras, reveals that the CD rim is more unstable than previously thought. Evidence for significant ground deformation between 2008 and 2015 has been presented in four sites. Moreover, fracture-widening rates have indicated an acceleration of the process since the reactivation of volcanic activity in 2014. In three of these sites, parts of the rim suddenly topple after periods of fracture extension and widening, whereas in the fourth one, a large part of the southern rim slides towards the caldera centre. These results cause concern, as the most attractive part of the caldera rim for visitors (outside the official track) includes the first two sites in the northwest.

Multi-temporal SfM is an efficient method to follow small-scale surface processes and is now routinely used at OVPF, in addition to the permanent instrumentation. The low cost and increasing precision of SfM open up new opportunities for comprehensive morphological monitoring of PdF. This is an ongoing project, and the 2015-2019 period will be studied in a similar way, but with datasets showing higher temporal resolution. 


\section{Acknowledgements}

The seismic and GNSS data presented in this paper were collected by Observatoire Volcanologique du Piton de la Fournaise, Institut de Physique du Globe de Paris, and Laboratoire GéoSciences Réunion of Université de La Réunion both included in UMR 7154 CNRS. We greatly acknowledge people of those two laboratories who have participated to the different technical or acquisition campaigns. We are grateful to the Editor and three anonymous reviewers whose comments greatly improved the manuscript. This is IPGP contribution $n^{\circ} 3980$.

\section{Declaration of conflicting interests}

The author(s) declared no potential conflicts of interest with respect to the research, authorship, and/or publication of this article.

\section{Funding}

The author(s) disclosed receipt of the following financial support for the research, authorship, and/ or publication of this article: This work was supported by the ANR (Agence Nationale de la Recherche) through the SLIDEVOLC project (contract number ANR-16-CE04-004-01).

\section{ORCID iD}

Allan Derrien (D) https://orcid.org/0000-0002-0128-
$854 \mathrm{X}$

\section{Note}

Raw photographs used in this study are available by contacting the Observatoire Volcanologique du Piton de la Fournaise (+262 (0)2 62275292$)$ or by mail at der rien@ipgp.fr or nicolas.villeneuve@univ-reunion.fr. Seismic and GNSS data used for comparison and doublechecking are directly available via the VOLOBSIS Portal: http://volobsis.ipgp.fr. Full PhotoScan reports of SfM processing for each date used in this study are available on researchgate (https://www.researchgate.net/profile/Allan_ Derrien/contributions). Their naming convention is YYYYMMDD_DolomieuCrater_Photoscan.

\section{References}

Bolognesi M, Furini A, Russo V, et al. (2015) Testing the lowcost RPAS potential in 3D cultural heritage reconstruction. International Archives of Photogrammetry, Remote Sensing \& Spatial Information Sciences XL-5/W4: 229-235.
Derrien A and Villeneuve N (2018) PhotoScan reports YYYYMMDD_DolomieuCrater_Photoscan. DOIs: 10. 13140/RG.2.2.18826.36804, 10.13140/RG.2.2.32248. 14084, 10.13140/RG.2.2.15470.92486, 10.13140/RG. 2.2.24698.39366, 10.13140/RG.2.2.31409.28009, 10 . 13140/RG.2.2.28053.83683, 10.13140/RG.2.2.34764. 72328.

Derrien A, Villeneuve N, Peltier A, et al. (2015) Retrieving 65 years of volcano summit deformation from multitemporal Structure-from-Motion: The case of Piton de la Fournaise (La Réunion Island). Geophysical Research Letters 42: L064820.

Froger JL, Famin V, Cayol V, et al. (2015) Timedependent displacements during and after the April 2007 eruption of Piton de la Fournaise, revealed by interferometric data. Journal of Volcanology and Geothermal Research 296: 55-68.

Got JL, Peltier A, Staudacher T, et al. (2013) Edifice strength and magma transfer modulation at Piton de la Fournaise volcano. Journal of Geophysical Research: Solid Earth 118(9): 5040-5057.

Heid T and Kääb A (2012) Repeat optical satellite images reveal widespread and long term decrease in landterminating glacier speeds. Cryosphere 6: 467-478.

Hibert C, Mangeney A, Grandjean G, et al. (2014) Automated identification, location, and volume estimation of rockfalls at Piton de la Fournaise volcano. Journal of Geophysical Research: Earth Surface 119: 1082-1105.

Hibert C, Mangeney A, Grandjean G, et al. (2017), Spatiotemporal evolution of rockfall activity from 2007 to 2011 at the Piton de la Fournaise volcano inferred from seismic data. Journal of Volcanology and Geothermal Research 333: 36-52.

Hungr O, Leroueil S and Picarelli L (2014) The Varnes classification of landslide types, an update. Landslides 11(2): 167-194.

Jacquard F (2009) Etude de vulnérabilité humaine via la perception des risques sur les sentiers de randonnées pédestre de l'Ile de La Réunion. Mémoire de Master II de Géographie. Université de La Réunion, France.

Jacquard F and Villeneuve N (2011) Perception des risques sur les sentiers de randonnées pédestre de l'ile de La Réunion -Etude de cas: Ravine Saint-Gilles et des sentiers du Piton de la Fournaise. In: Les Hauts de La Réunion, terres de tradition et d'avenir. Université de La Réunion - Océan Editions - Sous la direction de J. M. Jauze, 295-311. 
Kääb A and Leprince S (2014) Motion detection using near-simultaneous satellite acquisitions. Remote Sensing of Environment 154: 164-179.

Koenderink JJ and Van Doorn AJ (1991) Affine structure from motion. Journal of the Optical Society of America A: Optics, Image \& Science 8(2): 377-385.

Lénat JF and Bachèlery P (1990) Structure and dynamics of the central zone of Piton de la Fournaise volcano. In: Lénat J-F (ed) Le volcanisme de la Réunion-Monographie. La Réunion, France: Centre de Recherche en Volcanologie, 257-296.

McGuire WJ (1996) Volcano instability: a review of contemporary themes. Geological Society, London, Special Publications 110(1): 1-23.

Merle O, Michon L and Bachèlery P (2008) Caldera rim collapse: A hidden volcanic hazard. Journal of Volcanology and Geothermal Research 177(2): 525-530.

Michon L, Di Muro A, Villeneuve N, et al. (2013) Explosive activity of the summit cone of Piton de la Fournaise volcano (La Réunion island): A historical and geological review. Journal of Volcanology and Geothermal Research 264: 117-133.

Michon L, Massin F, Famin V, et al. (2011) Basaltic calderas: Collapse dynamics, edifice deformation, and variations of magma withdrawal. Journal of Geophysical Research: Solid Earth 116(B3): B03209.

Michon L, Staudacher T, Ferrazzini V, et al. (2007) April 2007 collapse of Piton de la Fournaise: A new example of caldera formation. Geophysical Research Letters 34: L21301.

Michon L, Villeneuve N, Catry T, et al. (2009) How summit calderas collapse on basaltic volcanoes: New insights from the April 2007 caldera collapse of Piton de la Fournaise volcano. Journal of Volcanology and Geothermal Research 184: 138-151.

Morin J, Jacquard F and Villeneuve N (2010) Piton de la Fournaise, a roped off volcano? Consequences of the 2007 "eruption of the century". In: Cities on volcano 6 , Tenerife, Canary Islands, Spain, 31 May-4 June 2010.

Peltier A, Bachèlery P and Staudacher T (2009) Magma transport and storage at Piton de La Fournaise (La Réunion) between 1972 and 2007: A review of geophysical and geochemical data. Journal of Volcanology and Geothermal Research 184(1): 93-108.

Peltier A, Got JL, Villeneuve N, et al. (2015) Long-term mass transfer at Piton de la Fournaise volcano evidenced by strain distribution derived from GNSS network. Journal of Geophysical Research: Solid Earth 120: 1874-1889.

Peltier A, Massin F, Bachèlery P, et al. (2012) Internal structures and building of basaltic shield volcanoes: The example of the Piton de La Fournaise terminal cone (La Réunion). Bulletin of Volcanology 74: 1881-1897.

Peltier A, Staudacher T and Bachèlery P (2007) Constraints on magma transfers and structures involved in the 2003 activity at Piton de La Fournaise from displacement data. Journal of Geophysical Research: Solid Earth 112(B3): B03207.

Roult G, Peltier A, Taisne B, et al. (2012) A new comprehensive classification of the Piton de la Fournaise eruptions spanning the 1986-2011 period. Search and analysis of eruption precursors from a broad-band seismological station. Journal of Volcanology and Geothermal Research 241-242: 78-104.

Staudacher T, Ferrazzini V, Peltier A, et al. (2009) The April 2007 eruption and the Dolomieu crater collapse, two major events at Piton de la Fournaise (La Réunion Island, Indian Ocean). Journal of Volcanology and Geothermal Research 184: 126-137.

Stieltjes L and Moutou P (1989) A statistical and probabilistic study of the historic activity of Piton de la Fournaise, Reunion Island, Indian Ocean. Journal of Volcanology and Geothermal Research 36(1-3): 67-86.

Turner D, Lucieer A and Watson C (2012) An automated technique for generating georectified mosaics from ultra-high-resolution unmanned aerial vehicle (UAV) imagery, based on Structure-from-Motion (SfM) point clouds. Remote Sensing 4(5): 1392-1410.

Villeneuve N and Bachèlery P (2006) Revue de la typologie des eruptions au Piton de la Fournase, processus et risqué volcaniques associés. Cybergeo: European Journal of Geography 30: 336. 


\section{Appendix}
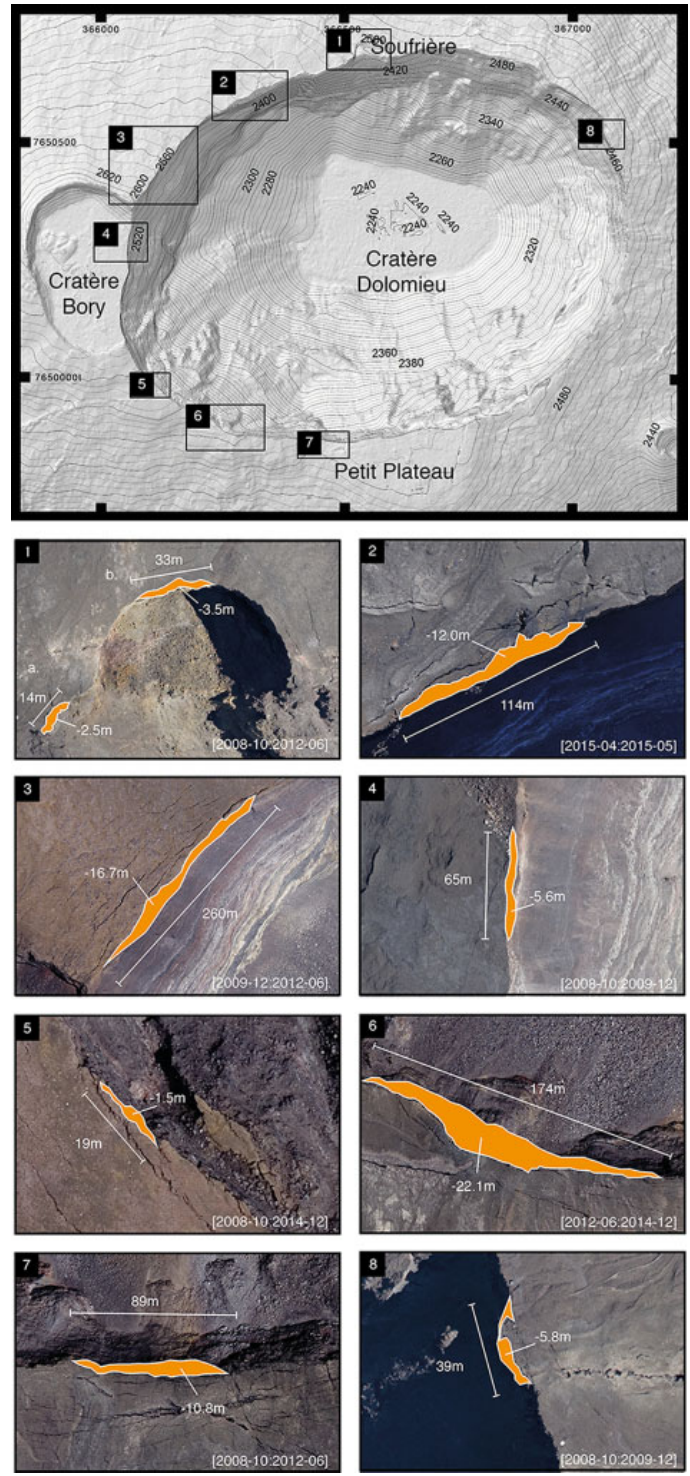

Annex I. Aerial pictures of the Cratère Dolomieu rim after the 2007 collapse, showing the areas where the edge greatly receded between April 2008 and May 2015. The dates in the lower right-hand side of each inset indicate the period during which the receding occurred. Details: (I) extension of the caldera edge of $2.5 \mathrm{~m}$ over a distance of I 4 m; 3.5 m over 33 m (inside the Soufrière Pit Crater); (2) I 2 m on II 4 m long; (3) I6.7 m on $260 \mathrm{~m}$ long; (4) $5.6 \mathrm{~m}$ on $65 \mathrm{~m}$ long; (5) $1.5 \mathrm{~m}$ on $19 \mathrm{~m}$ long; (6) $22.1 \mathrm{~m}$ on $174 \mathrm{~m}$ long; (7) $10.8 \mathrm{~m}$ on $89 \mathrm{~m}$ long; (8) $5.8 \mathrm{~m}$ on $39 \mathrm{~m}$ long. Coordinates in meters (WGS84, UTM $40 \mathrm{~S}$ ). 


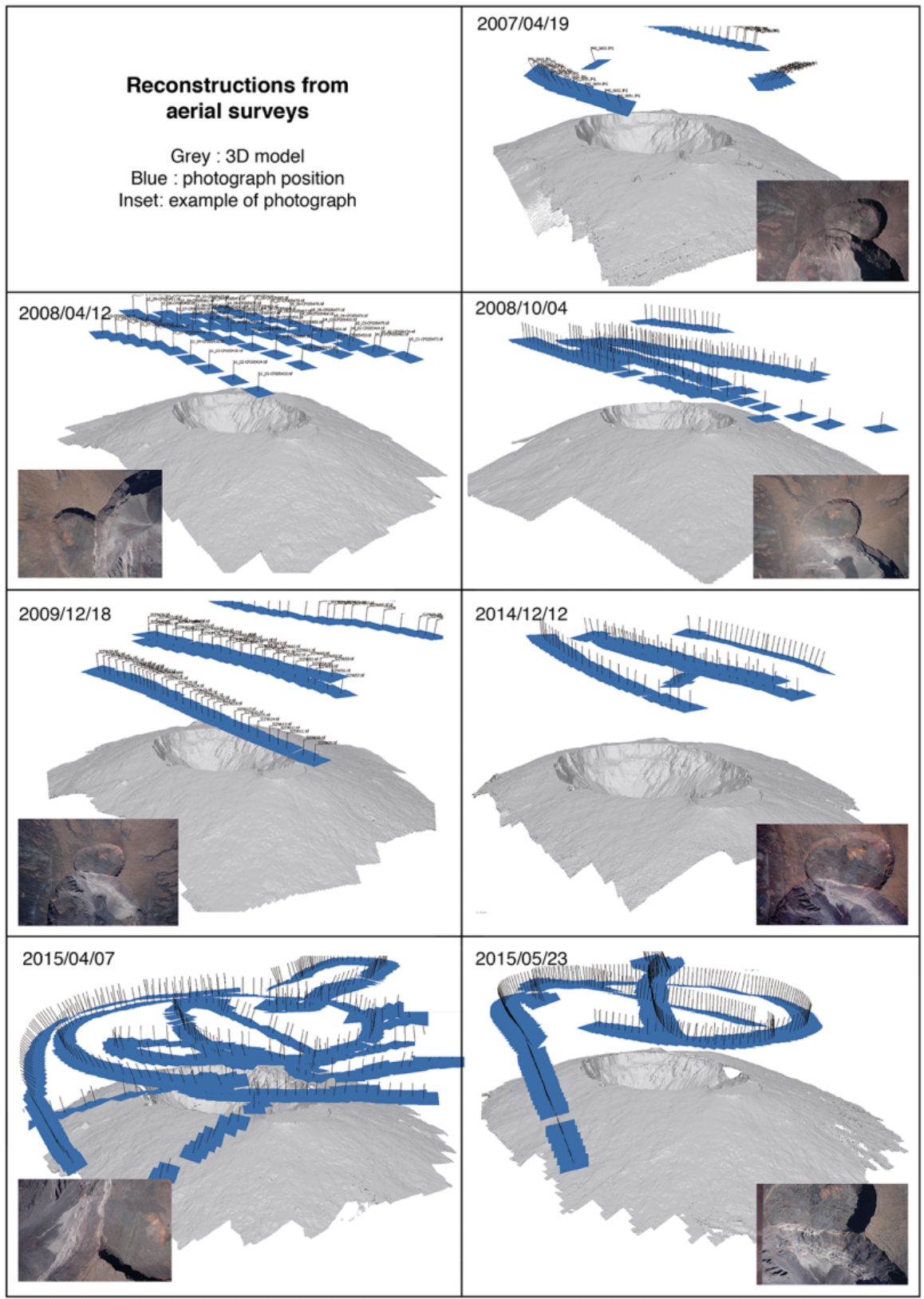

Annex 2. 3D models used in this study. Blue squares represent the position and orientation of the aerial photographs used for SfM reconstruction. Insets are examples of the survey photographs. 


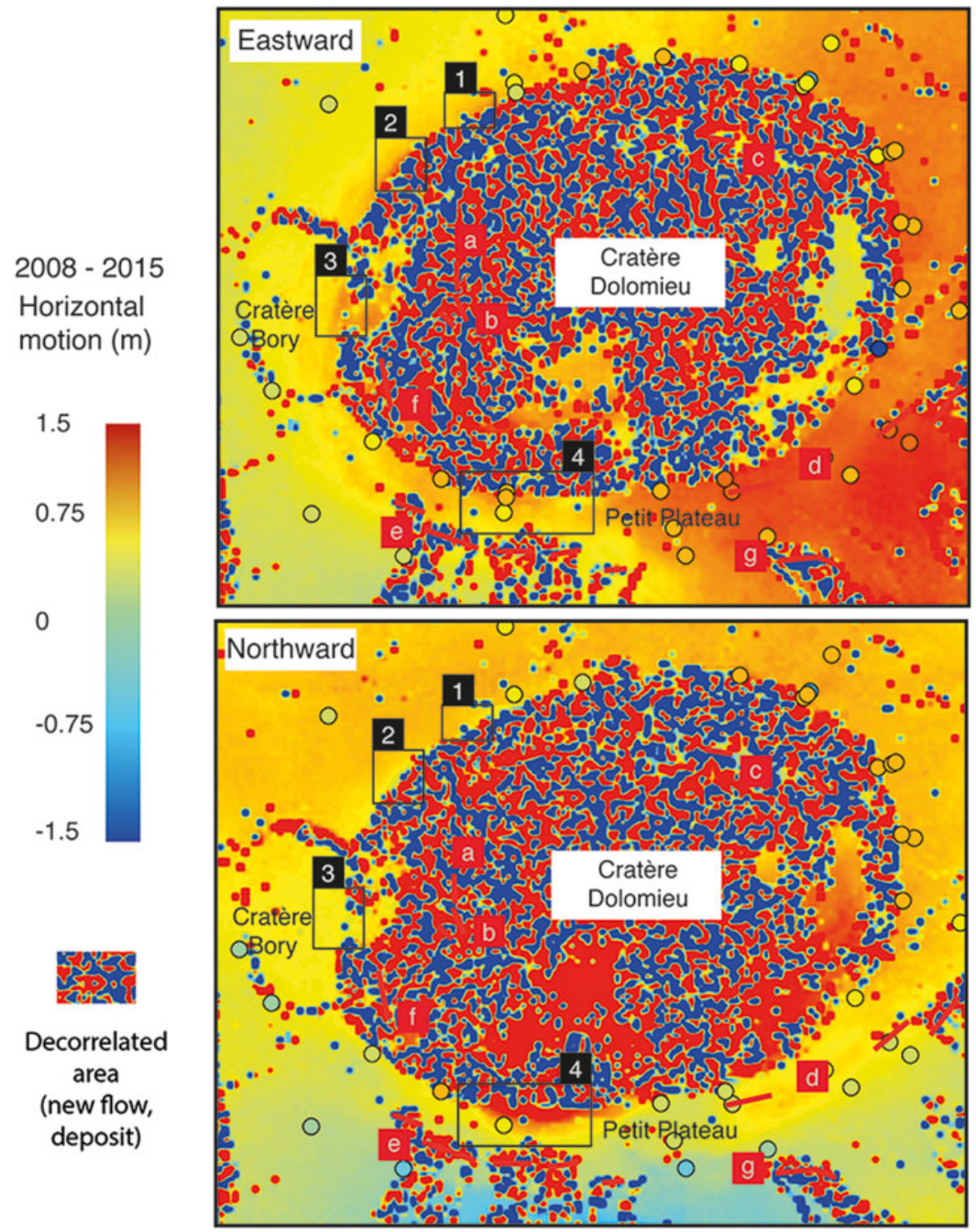

Annex 3. Horizontal ground motion between April 2008 and April 2015, as computed by 2D ortho-image cross-correlation. (a) E-W component (positive: eastward motion), dots represent the value measured on GNSS benchmarks for the same period for the sake of consistency (b) The same for N-S component (positive: northward motion). 